\title{
Teoria da Interdependência: os conceitos de sensibilidade e vulnerabilidade nas Organizações Internacionais
}

\author{
Interdependence theory: the concepts of sensitivity and vulnerability in International \\ Organizations
}

Noeli Rodrigues ${ }^{1}$

\begin{abstract}
RESUMO
O objeto de estudo do boletim é a análise dos conceitos de sensibilidade e vulnerabilidade nas Organizações Internacionais, sob a perspectiva da Teoria da Interdependência. O problema proposto concentra-se em desvendar como os conceitos de sensibilidade e vulnerabilidade explicam a atuação das Organizações Internacionais. A efetividade das ações das OIs evidencia o grau de eficácia da sua atuação. A Teoria da Interdependência é a teoria utilizada, pois explica a necessidade tanto de ações, quanto de soluções rápidas e eficazes no contexto internacional. Conclui-se que atuação das OIs se adapta a interesses inerentes a política internacional.
\end{abstract}

Palavras-chave: Teoria da Interdependência; Organizações Internacionais; Política Internacional.

\begin{abstract}
The object of study of the report is the analysis of the concepts of sensitivity and vulnerability in international organizations, from the perspective of the Theory of Interdependence. The proposed problem focuses on unraveling how the concepts of sensitivity and vulnerability explain the role of international organizations. The effectiveness of the actions of HIs shows the degree of effectiveness of its operations. The Theory of Interdependence theory is used, it explains the need for both actions, as quick and effective solutions in the international context. It was concluded that performance of HIs fits the interests inherent in international politics.
\end{abstract}

Keywords: Theory of Interdependence; International Organizations; International Politics.

\section{Introdução}

O tema abordado é a análise dos conceitos de sensibilidade e vulnerabilidade nas Organizações Internacionais atuação das Organizações Internacionais. Entende-se que, a sensibilidade e vulnerabilidade moldam a atuação das Organizações Internacionais e atendem desse modo, a interesses específicos e relevantes na política internacional.

\footnotetext{
${ }^{1}$ Mestranda em Ciência Política, Universidade Federal do Paraná(UFPR) e pesquisadora do Núcleo de Pesquisa em Relações Internacionais (NEPRI/UFPR), Curitiba, Brasil.
} 
O problema analisado no decorrer do boletim concentra-se em desvendar como os conceitos de sensibilidade e vulnerabilidade explicam a atuação das Organizações Internacionais. Nesse contexto, tanto a sensibilidade quanto à vulnerabilidade explicam a atuação das Organizações Internacionais na política internacional.

A discussão quanto à efetividade das ações, bem como seus resultados e o respeito da Sociedade Internacional evidencia a eficácia da atuação das Organizações Internacionais. A análise será conduzida sob o aparato teórico da Teoria da Interdependência, para analisarmos a atuação das Organizações Internacionais.

Para elucidar a problemática apresentada utilizaremos o princípio abarcado em tal teoria, como a sensibilidade e vulnerabilidade. Isto por que a teoria considera a cooperação entre os atores internacionais, ou seja, as Organizações Internacionais e os Estados Nacionais interdependentes e que embora se relacionem entre si, cada qual busca seus interesses e utilizam para tal objetivo o seu poder de influência e barganha na Sociedade Internacional, bem como o uso de suas capacidades.

\section{A Aplicação da Teoria da Interdependência no Cenário Internacional}

Pretende-se explicar com base na Teoria da Interdependência como os conceitos de sensibilidade e de vulnerabilidade determinaram as ações das Organizações Internacionais e suas decisões no que tange a política internacional.

O aporte da Teoria da Interdependência apresenta a atuação dos atores internacionais, isto é, o comportamento dos Estados e das Organizações no cenário internacional. Analisa-se o comportamento desses atores devido a sua abrangência e influência, a partir da década de 1970, nas Relações Internacionais.

A teoria é relevante para elucidar as questões, seja a influência dos atores internacionais ou o processo de negociação dentro das suas esferas, considerando a atuação e a eficácia das organizações internacionais e sua relevância a nível global. Nesse sentido, o aparato da teoria será utilizado para respaldar a análise quanto à eficácia na atuação das Organizações. 
A teoria pretende esclarecer de forma coerente e sistemática os elementos do conhecimento acerca da realidade. Fernandes (2004) considera que a base teórica consiste no processo contínuo de desenvolvimento, de modo que esse aporte explique o objeto de estudo de acordo com a realidade.

Para tornar possível o esclarecimento, estabeleceremos as relações entre esses elementos e suas causalidades, desse modo, tais elementos serão verificados por análises baseadas na realidade social internacional e suas especificidades (FERNANDES, 2004, p.38-39).

Entre as décadas de 1960 e 1970 os pressupostos realistas passaram por um processo de contestação, iniciado pelos trabalhos dos autores Robert Keohane e Joseph Nye, chamados de transnacionalistas, tal aporte teórico traria uma visão alternativa, em relação às teorias já existentes, ou seja, contrapondo-se as teorias idealista e realista. Os autores analisam de que forma a política internacional interfere no comportamento estatal, por isso, a necessidade de compreender o contexto mundial.

Entretanto, Nye (2003) enfatiza que, ainda que os Estados ocupem destaque na política internacional esses atores que outrora dominavam, passaram a dividir a arena internacional com os demais atores. Entretanto, os Estados não devem ser subestimados, visto que exercem influência sobre os demais agentes. Esses novos agentes não possuem força normativa suficiente para impor sua vontade dentro do território estatal, mas podem influenciar o processo de decisões internacionais (DI SENA JUNIOR, 2003).

A interdependência aborda a cooperação recíproca, ou seja, dependência mútua e contempla a interferência de forças externas que influenciam atores em diversos países. A teoria não afirma que a arena internacional seja um ambiente de cooperação apenas, mas que no jogo para obter os resultados propostos é necessário manipular os fatores de interdependência. Tais assimetrias são consideradas fontes de poder entre os atores.

Essas assimetrias na arena global aumenta a complexidade do sistema, e torna o cenário internacional um ambiente de coalizões mais complexas, de modo que 
diferentes formas de poder são utilizadas. Desse modo, os conflitos ocorrem entre os atores da arena internacional com interesses opostos (DI SENA JUNIOR, 2003, p.188189).

A interdependência de acordo com Oliveira (2005) implica em custos e redução da autonomia. Por isso, não se pode prever qual a relação de custo benefício, pois pode variar de acordo com os critérios utilizados entre as partes envolvidas. A interação entre os atores se refere a um jogo que comanda a ação desses atores a partir de negociações (OLIVEIRA, 2005, p. 123-126).

A interdependência abarca a concepção de sociedade internacional, ou seja, ambiente em que os Estados partilham de interesses e valores comuns e são interligados por um conjunto de regras através de instituições comuns que estabelecem regras também comuns responsáveis por orientar tais relações (FERNANDES, 2004).

\section{A Atuação dos Atores na Sociedade Internacional}

Considerando que, se os Estados estão inseridos na Sociedade Internacional significa que esses atores reconhecem interesses e valores comuns, como por exemplo, a responsabilidade com os compromissos assumidos, o respeito por regras no tocante ao uso da força entre si. Outro valor seria o respeito mútuo pela interdependência de cada um e consequentemente a cooperação desses atores no funcionamento das instituições, isto é, a cooperação relacionada ao Direito Internacional, que abarca os costumes e as convenções de guerra, bem como, o sistema de diplomacia e as organizações internacionais (FERNANDES, 2004, p.82 e 88).

As Instituições Internacionais se constituem em agentes que atuam no cenário internacional, ou seja, essas instituições são utilizadas como parte dos jogos como instrumentos de barganha. A atuação desses atores fortalecem os pequenos Estados e demonstram que um conflito não pode ser vencido apenas com o uso da força física. Santos Junior (1999, p.79.) explica que a perspectiva teórica interdependente expõe o choque de interesses que contrapõem os Estados. Isso porque há entre os Estados um poder desigual, fato que influencia na realização de projetos e nas estratégias estatais, 
no âmbito internacional. Para compreensão da relação entre os Estados grandes e pequenos o autor sugere a seguinte explicação

A metáfora da interdependência como mesa de negociação tem como base a construção de um cenário, onde, em torno de uma mesa, grandes e pequenos países apresentam listas de negociações, sendo que a [lista] dos países ricos são maiores (SANTOS JUNIOR, 1999, p.86).

A mesa de negociações a que o autor se refere pode ser entendida como que se situa no âmbito das Organizações Internacionais, que abarcam diversos países, grandes e pequenos, ricos e pobres. Esses países por sua vez, apresentam muitas assimetrias. Tais assimetrias geram a necessidade de cooperação entre os Estados, a fim de que haja o desenvolvimento desses países, porém aqueles que possuem maior desenvolvimento mantém o controle sobre as questões que são de seu interesse. Visto que o poder de influência estatal continua a ter sua importância, de acordo com Santos Junior (1999, p.80). A observação comprova que apesar do poder militar ter sua relevância não deve ser o único instrumento nas relações internacionais, principalmente nas relações entre Estados e organizações internacionais (DI SENA JUNIOR, p.195,2003).

A importância dessas organizações não está na sua representatividade referente à cooperação ou na prescrição de regras aos governos, mas nas articulações de acordo entre as partes, de modo que tais acordos sejam satisfatórios para ambos os envolvidos. Podemos entender que as regras estabelecidas para a ação na arena internacional são denominadas de regimes que regem os atores no contexto internacional (DI SENA JUNIOR, 2003).

Essas organizações agem como instrumento eficaz de negociação na barganha entre os países. Portanto a Interdependência é caracterizada por uma disputa assimétrica entre os atores, uma arena de conflito e de cooperação, que obtêm como resultados; perdas e ganhos, em maior ou menor proporção. Geralmente, nesse jogo todos ganham, não há perdedores, de tal forma que se transformam em dependentes uns dos outros (DI SENA JUNIOR, 2003).

\section{A Sensibilidade e a Vulnerabilidade}

De acordo com a Teoria da Interdependência, há duas dimensões em que o poder se manifesta, são elas a sensibilidade e a vulnerabilidade. Tal manifestação do poder se 
refere à maneira com que os recursos são utilizados frente a outro ator a fim de influenciar diretamente no resultado de determinada situação. De modo que, a sensibilidade significa o potencial de resposta de um país em relação a outro. Isto é, a capacidade de resposta política frente a uma ação que possa afetar de modo significativo à política interior do país.

A vulnerabilidade, diferente da sensibilidade, retrata não a capacidade de resposta, mas a possibilidade de determinado país de influenciar no resultado das ações de outro país. Sendo que dessas dimensões ocorrem resultados que podem ser imediatos (sensibilidade) ou de curto e médio prazo (vulnerabilidade). Portanto, o grau de influência e de controle de resultados, em maior ou menor grau, se resume aos conceitos de sensibilidade e vulnerabilidade (RICOBOM, 2003, p.254-255).

Tais dimensões influenciam os atores internacionais nos planos interno e externo: a sensibilidade refere-se ao impacto interno que as alterações em âmbito internacional causam. Por outro lado, a vulnerabilidade é demonstrada a partir da capacidade de um ator de enfrentar as mudanças no cenário internacional, bem como os custos provenientes dessas mudanças. Esta dimensão se destaca como elemento determinante na política internacional, pois se o ator em questão for menos vulnerável possuirá maior poder de barganha e possibilidade de estratégias nas relações internacionais, mas essa influência acarretará riscos (ALVES, 2003, p. 356).

A sensibilidade e a vulnerabilidade são fatores que influenciam os resultados no contexto da interdependência, pois estão relacionadas com o poder. De modo que, se transformam em fontes de poder e são utilizados pelas Organizações Internacionais e os Estados para alcançar seus objetivos, sejam eles imediatos ou não. Então tais fatores insidiem sobre os jogos nas Relações Internacionais e influenciam os resultados (ganhos ou perdas) através da sensibilidade e da vulnerabilidade, considerando os riscos. Essas dimensões são responsáveis pela manutenção do poder por parte de alguns Estados e sustentam seus interesses e ideologias (LIMA, 2003, p. 278-279).

Entende-se que os países que fazem parte dessas organizações como as Nações Unidas são menos vulneráveis que os países em conflitos, por exemplo. Isso por que 
países como os Estados Unidos têm condições militares e econômicas de enfrentar as situações em âmbito internacional oferecendo respostas imediatas a quaisquer questões, seja envolvendo a sensibilidade ou a vulnerabilidade, pois esses conceitos explicam a disparidade que há entre os países maiores que compõem as OIs. Aqueles países que não possuem capacidade de enfrentar e responder prontamente as situações assimétricas em conflitos são considerados mais sensíveis, sendo que os danos são mais perceptíveis (LIMA, 2003, p. 279-280).

Isso se explica, segundo Sarfati (p.165, 2005), pelo custo e a disponibilidade de recursos, pois os países periféricos não possuem alternativas suficientes para oferecerem respostas rápidas e os recursos são menores. De acordo com Nogueira e Messari (2005, p.95) as organizações agem de modo que maximizem seus ganhos de curto prazo através da barganha e incentivem condutas cooperativas ao demonstrarem crescentes benefícios mútuos. A responsabilidade quanto ao comportamento dos envolvidos, fortalece e favorece os regimes, bem como as negociações, visto que a atuação dessas instituições influencia na formação e na mudança dos interesses estatais. Ainda de acordo com os autores, estruturas de autoridade de alcance mundial são importantes, mesmo que essas estruturas se configurem na diminuição da autonomia dos Estados, dada a abrangência das organizações internacionais. 0 que ocorre de fato é que de acordo com o comportamento dos atores envolvidos são analisadas as consequências e as possibilidades, bem como as alianças que evidenciem maiores benefícios.

consideram fundamental a atuação das organizações internacionais, pois favorecessem, no sentido de intermediar o cumprimento de tais acordos e consequentemente a cooperação. Esse processo se estabelece por meio de parâmetros para as negociações. Herz e Hoffmann (2004, p.55)

De acordo com Young (2000), a efetividade das instituições é a forma de medir o desempenho dessas de modo a determinar a conduta individual ou coletiva. Para o autor, eficiência e equidade são resultados da atuação de instituições muito efetivas, mas não se pode garantir que tais resultados sempre respeitarão esses critérios de avaliação. Com isso, constatamos que há diversos fatores que contribuem para a ação efetiva das 
Organizações Internacionais, situação que compromete, de certo modo, o sucesso dos processos que estão a cargo dessas organizações.

\begin{abstract}
Ao avaliar a efetividade das instituições internacionais, precisamos atentar para a conduta dos Estados não só reagindo às decisões tomadas em seu nome pelas instituições internacionais como na implementação de regimes, de modo a assegurar que os que se encontram sob a sua jurisprudência respeitem igualmente as exigências institucionais (YOUNG, 2000, p. 32).
\end{abstract}

Segundo com DI SENA JÚNIOR (2003) a atuação das Organizações Internacionais apresentaram falhas, pois autores consideram a criação das Nações Unidas, parte da consolidação do poder hegemônico dos Estados Unidos sobre os outros países. Pois os EUA recorrem a Organização das Nações Unidas e a Organização do Tratado do Atlântico Norte (OTAN), organizações internacionais, para legitimar suas ações militares, como por exemplo, o ataque à ex-Iugoslávia. Dominação que o autor Di Sena Júnior (p.203,2003) denomina como "tríade": Estados Unidos, Japão e União Europeia, e nas palavras dos autores, um condomínio político exercido pelos membros permanentes do Conselho de Segurança das Nações Unidas (DI SENA JÚNIOR, 2003).

\title{
Considerações Finais
}

O presente boletim demonstrou como os conceitos de sensibilidade e vulnerabilidade são relevantes para a atuação das organizações internacionais na perspectiva da Teoria da Interdependência. Pois, tanto a sensibilidade quanto à vulnerabilidade moldam a atuação e as decisões dos atores na política internacional.

Nesse aspecto, as organizações tornaram-se um importante fórum de debate e negociação e, consequentemente, um espaço de barganha e disputas entre os atores. Essas disputas ocorrem devido às assimetrias e a disponibilidade de recursos que existem entre os países, no Sistema Internacional.

Os países barganham no Sistema Internacional de acordo com as capacidades que possuem. Desse modo, a sensibilidade e vulnerabilidade (segundo a Teoria da Interdependência) determinam a resposta de cada país na política internacional. Nesse 
aspecto, os países maiores conseguem maior poder de barganha no âmbito das organizações internacionais.

Outra constatação se refere à capacidade que os atores, países ou organizações internacionais, possuem de apresentar [de acordo com seus recursos] respostas rápidas e eficazes as demandas no cenário internacional. Demonstrando, dessa maneira, como os conceitos de sensibilidade e vulnerabilidade moldam a atuação das OIs na política internacional.

Conclui-se que as capacidades e os recursos de uma organização internacional determinam sua atuação, e consequentemente, seus ganhos e perdas. Países maiores, por exemplo, têm maior potencial de resposta (sensibilidade) em relação aos países menores, e têm maior possibilidade de influenciar a ação (vulnerabilidade) de outros atores ou organizações no contexto internacional, por isso a probabilidade de ganho e barganha torna-se significativa, em relação aos países menores.

\section{Referências Bibliográficas}

ALVES, Patrícia Vignolo. A Interdependência Complexa e os Direitos Humanos. In: OLIVEIRA, Odete Maria de; DAL RI, Arno Jr. (org.). Relações Internacionais: Interdependência e Sociedade Global. Rio Grande do Sul: Unijuí, 2003, p. 356.

DI SENA JUNIOR, Roberto. Poder e Interdependência: Perspectivas de Análise das Relações Internacionais na Ótica de Robert O. Keohane e Joseph S. Nye. In: OLIVEIRA, Odete Maria de; DAL RI, Arno Jr. (org.). Relações Internacionais: Interdependência e Sociedade Global. Rio Grande do Sul: Unijuí, 2003, p.179-210.

FERNANDES, José Pedro T. Teorias das Relações Internacionais: Da Abordagem Clássica ao Debate Pós-Positivista. Coimbra: Almedina, 2004.

HERZ, Mônica; HOFMANN, Andrea Ribeiro. Organizações internacionais: história e práticas. Rio de Janeiro: Elsevier, 2004.

LIMA, Rodrigo Carvalho de Abreu. Interdependência e Assimetria: Dilemas das Relações Internacionais Contemporâneas. In: OLIVEIRA, Odete Maria de; DAL RI, Arno Jr. (org.). Relações Internacionais: Interdependência e Sociedade Global. Rio Grande do Sul: Unijuí, 2003, p.278-279.

NOGUEIRA, João P.; MESSARI Nizar. Teoria das Relações Internacionais: Debates e Correntes. Rio de Janeiro: Elsevier, 2005. 
NYE, Joseph Jr. O Paradoxo do Poder Americano. São Paulo: UNESP, 2003.

OLIVEIRA, Odete Maria de. Relações Internacionais: Estudos de introdução. 2 a ed., 2004. Curitiba: Juruá, 2005.

RICOBOM, Gisele. Aspectos da Teoria da Interdependência no Contexto das Relações Internacionais Contemporâneas. In: OLIVEIRA, Odete Maria de; DAL RI, Arno Jr. (org.). Relações Internacionais: Interdependência e Sociedade Global. Rio Grande do Sul: Unijuí, 2003, p.254-255.

SANTOS JÚNIOR, Raimundo Batista dos. Processo Global: Relações Internacionais e a Interdependência Assimétrica. In: OLIVEIRA, Odete Maria de (org.) Relações Internacionais \& globalização: Grandes Desafios. Rio Grande do Sul: Ijuí, 1999, p. 6794.

SARFATI, Gilberto. Teoria das Relações Internacionais. São Paulo: Saraiva, 2005, p.191199.

YOUNG, Oran. A eficácia das instituições internacionais: Alguns Casos Difíceis e Algumas Variáveis Críticas. In Rosenau, James e Czempiel, Ernst-Otto. Governança sem governo. Ordem e transformação na política mundial. Ed. UNB. 2000. 